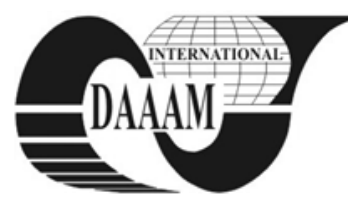

Annals of DAAAM for 2011 \& Proceedings of the 22nd International DAAAM Symposium, Volume 22, No. 1, ISSN 1726-9679 ISBN 978-3-901509-83-4, Editor B. Katalinic, Published by DAAAM International, Vienna, Austria, EU, 2011 Make Harmony between Technology and Nature, and Your Mind will Fly Free as a Bird Annals \& Proceedings of DAAAM International 2011

\title{
CONTROL OF ACTIVE SANITARY COACH
}

\author{
VOTRUBEC, R[adek]
}

\begin{abstract}
The paper deals with an enhanced control system of sprung sanitary coach. Active sanitary coach was developed in our hydrodynamic laboratory. It consists of parallelogram and two rotating frames. All frames are propelled by pneumatic springs. Measuring and control software was created in Labview. Inputs of control algorithm are pressures, positions and accelerations from all installed sensors. Coach is controlled to horizontal position of upper frame. The coach was excited by forces to upper frame and forces from three pistons of hydrodynamic pulsator. It is enabled to test the system during various loading and to simulate various drive conditions. Magnetorheological dampers were applied to upper frames
\end{abstract}

Key words: Sanitary coach, active stretcher, active suspension, magnetorheological damper, vibroinsulation, LabView

\section{INTRODUCTION}

Active sanitary coach prototype, see Fig.1, was developed in our hydrodynamic laboratory in terms of project Active vibroisolation under the auspices of Ministry of Education together with Active driver seat (Janecek et al., 2005). The main aim was to make sanitary coach more comfortable. We would like to reduce vibration amplitude of coach and eliminate natural frequency of system near $3 \mathrm{~Hz}$, which is very unpleasant to human body.

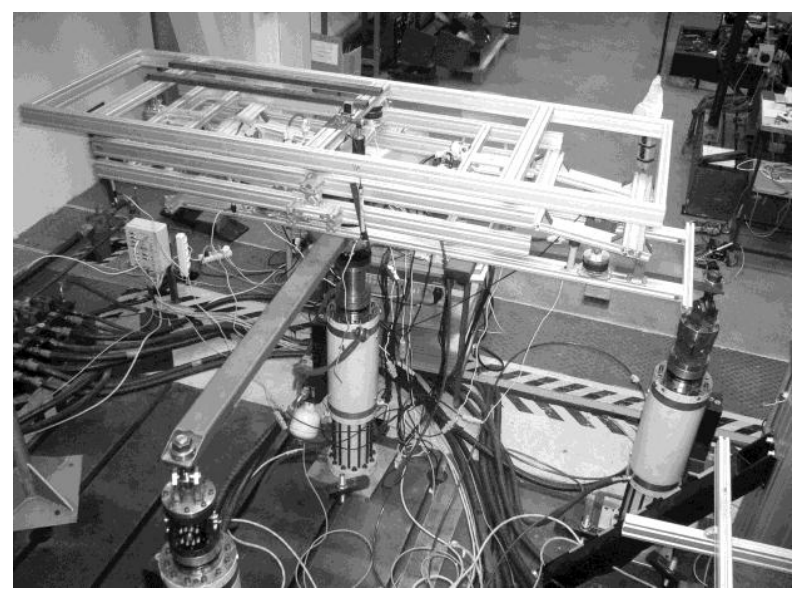

Fig. 1. Prototype of sanitary coach

\section{DESCRIPTION OF SANITARY COACH}

Active sanitary coach consists of three independent movable plates - parallelogram and two rotating frames. All frames are propelled by pneumatic springs. Each spring is equipped with electrical valve and pressure sensor. Next coach is equipped with three sensors of position, three sensors of relative acceleration and two-axial inclinometer, see Fig.2. All these elements are connected to measuring cards in PC. Measuring and control software was created in Labview.

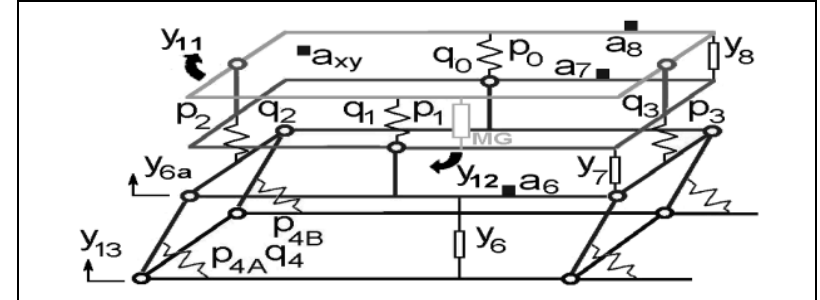

Fig. 2. Scheme of sanitary coach

\section{STRUCTURE OF CONTROL}

Scheme of the whole control system is in Fig. 3. PID controllers were designed for control pressure in each spring. Position loop was connected to control position of parallelogram $\mathrm{y}_{\mathrm{y} 6}$ with PI controller $\mathrm{R}_{\mathrm{y} 6}$. To improve quality of control an acceleration loop was added with controller $\mathrm{R}_{\mathrm{a} 6}$.

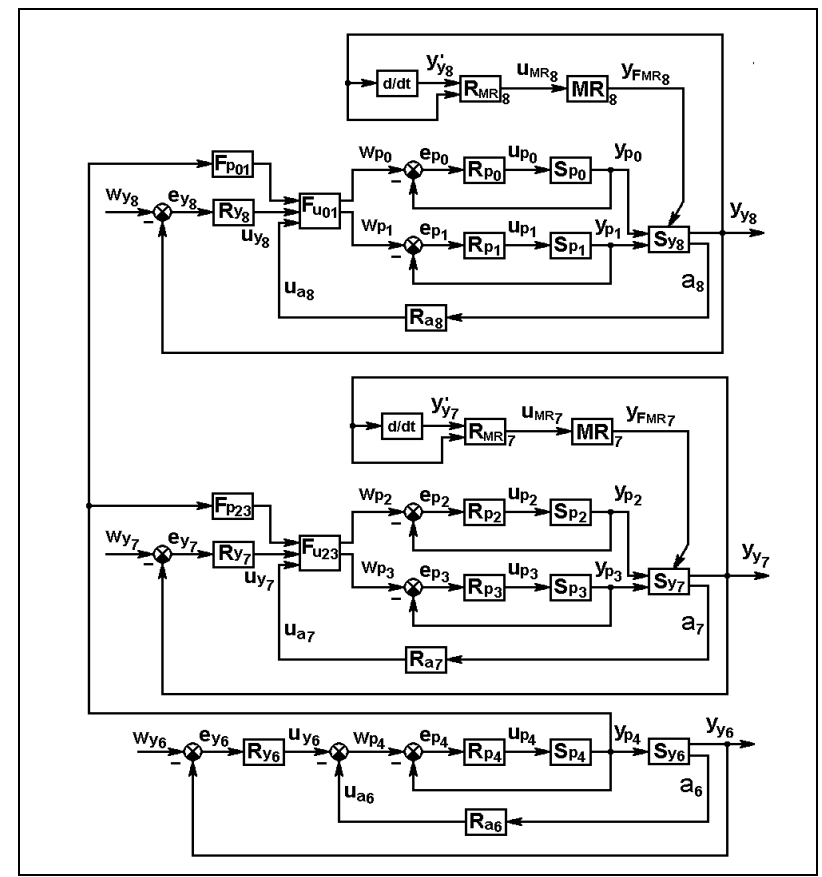

Fig. 3. Control structure of sanitary coach

Movement of each upper rotating frame is controlled by means of couple of springs. Sum of pressures in these springs is derived from pressure of parallelogram spring, and proportion of pressures is used as actuating variable for controlling of position of the upper frames $\mathrm{y}_{\mathrm{y} 7}$ and $\mathrm{y}_{\mathrm{y} 8}$. Acceleration feedbacks were added to each rotating frame with controllers $R_{a 7}$ and $R_{a 8}$. System is extended with two MR damper control loops with inspiration in (Shen et al., 2007). Identification and control of MR dampers were published in (Votrubec, 2003) and (Votrubec, 2009). Position signals from pistons of pulsator are built in to the model as disturbances. 
The coach can be excited by forces to upper frame or forces from three pistons of hydrodynamic pulsator. Input signals for hydraulic pistons were designed in own LabView application published in (Votrubec, 2008).

Parallelogram was tested with two configurations of springs, four smaller interconnected springs on each arm of parallelogram or only one bigger central spring. Four control methods of parallelogram were used. First method rests in controlling to constant pressure in main pneumatic spring $\mathrm{p}_{4}$. Coach is initialized to basic position by virtue of position feedback. Reached pressure is kept by means of pressure feedback. Second method rests in control to constant distance from coach base, see Fig.4a. Third method is control to constant absolute position compared with surrounding, see Fig.4b. Fourth method is combination of two previous cases. Position is controlled to minimize motion against surrounding, but its wanted value is not constant and it slowly inclines to middle distance from coach base, see Fig 4c.

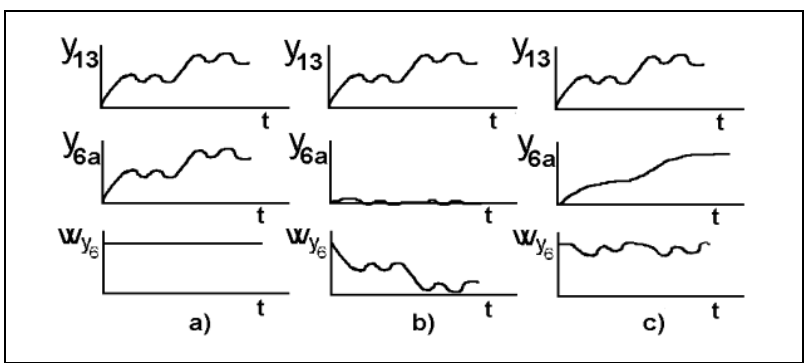

Fig. 4. Control strategy

\section{RESULTS OF CONTROL}

Results of control are presented in charts in Fig. 5. First graph shows position control of parallelogram. Grey course represents position of coach base. Position of top of parallelogram is displayed black. Second and third charts show control of upper rotating frames. Grey courses represent rotation of coach base and black courses represent rotations of upper frames that reach for horizontal position.

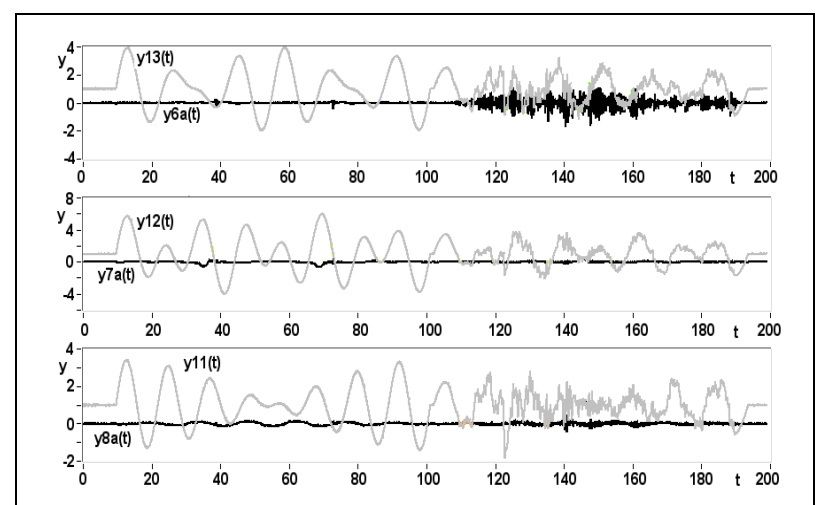

Fig. 5. Control of the parallelogram and upper rotating frames

It is necessary to find resonant frequency of coach. For that purpose set of chirp signal with frequency changing between 0,25 and $5 \mathrm{~Hz}$ was used as input of hydraulic pistons. Its course with response is in Fig.6.

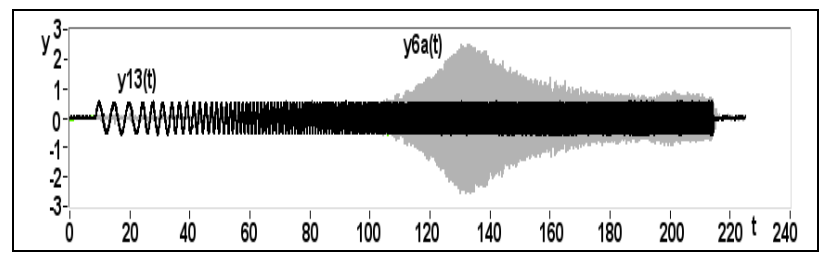

Fig. 6. Chirp input signal for parallelogram position
Frequency analysis of response from Fig.6 is in Fig.7. Resonant frequency of parallelogram is $1.74 \mathrm{~Hz}$. It is agreeable for human body.

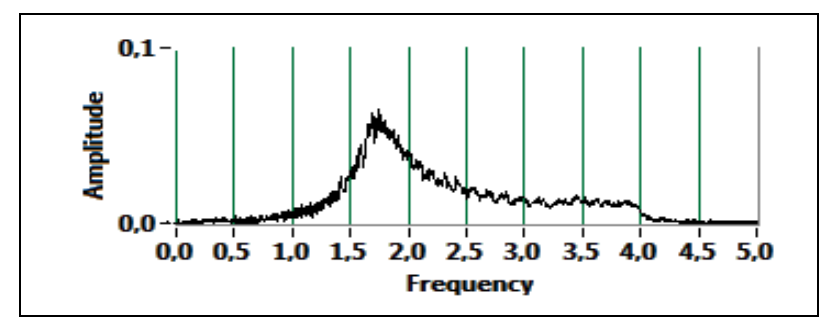

Fig. 7. Frequency analysis of parallelogram position

\section{CONCLUSION}

Control system of sanitary coach prototype was successfully projected, set and tested. Pressure, position and acceleration feedbacks were applied. Several control strategies of coach were introduced. Measurement application was created in LabView. Parameters of control circuits were adjusted with regard to actuating forces from three pistons of hydrodynamic pulsator. We reached good results of active control of coach suspension in sub-resonant area. In the future we are going to control coach using gyroscopic stabilizers. We introduced this problem on another platform in (Sivcak \& Votrubec, 2009). Next we are going to test standard hydraulic mechanically adjustable dampers instead of magnetorheological dampers. It will be cheaper option.

\section{ACKNOWLEDGEMENTS}

This work was supported by the subvention from Ministry of Education of the Czech Republic under Contract Code MSM 4674788501 .

\section{REFERENCES}

Janecek, B., Kupka, L., Sklíba, J., Apetaur, M., Martonka, R. (2005): On the Problem of the Active Control of the Driver Seat. Engineering Mechanics (International Journal for Theoretical and Applied Mechanics), 2005, no.A1, pages 309-316, ISSN 1210-2717

Shen, Y.; Golnaraghi, M.F. \& Heppler, G.R. (2007). Loadleveling suspension system with a magnetorheological damper, Vehicle System Dynamics, Taylor \& Francis 2007, pp. 297-312, ISSN 0042-3114

Sivcak, M, Votrubec, R (2009).: The Correction and Compensation Motors for the Gyroscopic Stabilizer, In: Mechatronic system and materials 2009, Vilnius Gediminas Technical University, Vilnius, Lithuania, p. 136-138, ISBN 978-9955-28-493-2

Votrubec, R. (2003). Global Characteristics of Dampers, Damping Elements and Other Mechanical Systems, In: DAAAM International Scientific Book 2003, DAAAM International Publisher Vienna, Sarajevo, Bosna, 2003, ISSN 1726-9687, ISBN 3-901509-36-4

Votrubec, R. (2008). Software for Generation of Actuating Signals for Dampers in LabView, In: Process Control 2008, Kouty nad Desnou, Czech Republic, 2008, page 208, ISBN 978-80-7395-077-4

Votrubec, R. (2009): Identification of Magnetorheological Damper, In: The 20th International DAAAM Symposium Intelligent Manufacturing \& Automation: Theory, Practice \& Education 2009, Annals of DAAAM for 2009 \& Proceedings of the 20th International DAAAM Symposium, ISBN 978-3-901509-70-4, ISSN 1726-9679, pp 896, Editor Branko Katalinic, Published by DAAAM International, Vienna, Austria 2009 